\title{
Reassessing the Role of Histaminergic Tuberomammillary Neurons in Arousal Control
}

\author{
-Anne Venner, ${ }^{1 \star}$ Takatoshi Mochizuki, ${ }^{2 \star}$ (Doberto De Luca, ${ }^{1}$ Christelle Anaclet, ${ }^{3}$-Thomas E. Scammell, ${ }^{1}$ \\ (DCClifford B. Saper, ${ }^{1}$ (DElda Arrigoni, ${ }^{1}$ and ${ }^{D}$ Patrick M. Fuller ${ }^{1}$ \\ ${ }^{1}$ Department of Neurology, Beth Israel Deaconess Medical Center and Division of Sleep Medicine, Harvard Medical School, Boston, Massachusetts 02215, \\ ${ }^{2}$ Graduate School of Science and Engineering, University of Toyama, Toyama 930-8555, Japan, and ${ }^{3}$ Department of Neurobiology, Brudnick \\ Neuropsychiatric Research Institute, NeuroNexus Institute, Graduate Program in Neuroscience-Graduate School of Biomedical Sciences, University of \\ Massachusetts Medical School, Worcester, Massachusetts 01655
}

The histaminergic neurons of the tuberomammillary nucleus $\left(\mathrm{TMN}^{\mathrm{HDC}}\right.$ ) of the posterior hypothalamus have long been implicated in promoting arousal. More recently, a role for GABAergic signaling by the TMN ${ }^{\mathrm{HDC}}$ neurons in arousal control has been proposed. Here, we investigated the effects of selective chronic disruption of GABA synthesis (via genetic deletion of the GABA synthesis enzyme, glutamic acid decarboxylase 67) or GABAergic transmission (via genetic deletion of the vesicular GABA transporter (VGAT)) in the TMN ${ }^{\mathrm{HDC}}$ neurons on sleep-wake in male mice. We also examined the effects of acute chemogenetic activation and optogenetic inhibition of $\mathrm{TMN}^{\mathrm{HDC}}$ neurons upon arousal in male mice. Unexpectedly, we found that neither disruption of GABA synthesis nor GABAergic transmission altered hourly sleep-wake quantities, perhaps because very few TMN ${ }^{\mathrm{HDC}}$ neurons coexpressed VGAT. Acute chemogenetic activation of TMN ${ }^{\mathrm{HDC}}$ neurons did not increase arousal levels above baseline but did enhance vigilance when the mice were exposed to a behavioral cage change challenge. Similarly, acute optogenetic inhibition had little effect upon baseline levels of arousal. In conclusion, we could not identify a role for GABA release by $\mathrm{TMN}^{\mathrm{HDC}}$ neurons in arousal control. Further, if TMN ${ }^{\mathrm{HDC}}$ neurons do release GABA, the mechanism by which they do so remains unclear. Our findings support the view that $\mathrm{TMN}^{\mathrm{HDC}}$ neurons may be important for enhancing arousal under certain conditions, such as exposure to a novel environment, but play only a minor role in behavioral and EEG arousal under baseline conditions.

Key words: chemogenetics; EEG/EMG; histidine decarboxylase; optogenetics; sleep; wake

\section{Significance Statement}

The histaminergic neurons of the tuberomammillary nucleus of the hypothalamus (TMN ${ }^{\mathrm{HDC}}$ ) have long been thought to promote arousal. Additionally, TMN ${ }^{\mathrm{HDC}}$ neurons may counter-regulate the wake-promoting effects of histamine through co-release of the inhibitory neurotransmitter, GABA. Here, we show that impairing GABA signaling from TMN ${ }^{\mathrm{HDC}}$ neurons does not impact sleep-wake amounts and that few TMN ${ }^{\mathrm{HDC}}$ neurons contain the vesicular GABA transporter, which is presumably required to release GABA. We further show that acute activation or inhibition of TMN ${ }^{\mathrm{HDC}}$ neurons has limited effects upon baseline arousal levels and that activation enhances vigilance during a behavioral challenge. Counter to general belief, our findings support the view that $\mathrm{TMN}^{\mathrm{HDC}}$ neurons are neither necessary nor sufficient for the initiation and maintenance of arousal under baseline conditions.

\section{Introduction}

A wake-promoting role for histaminergic neurons of the tuberomammillary hypothalamic nucleus (TMN) has long been pos-

Received May 7, 2019; revised Sept. 16, 2019; accepted Sept. 19, 2019.

Author contributions: A.V., T.M., C.A., T.E.S., C.B.S., E.A., and P.M.F. designed research; A.V., T.M., and R.D.L. performed research; A.V., T.M., and R.D.L. analyzed data; A.V., T.M., R.D.L., C.A., T.E.S., C.B.S., E.A., and P.M.F. wrote the paper.

This work was supported by Sleep Research Society Foundation Career Development Award 016-JP-17 and NARSAD Young Investigator's Grant 20964 to A.V.; G. Harold and Leila Y. Mathers Foundation HL095491 to C.B.S.; and NS073613, NS092652, and NS103161 to P.M.F.

We thank Lauren T. Sohn, Sathyajit Bandaru, Mihoko Yamamoto, Sara Hyde, Shoshi Freeman, Quan Ha, Minh Ha, Sarah Keating, Miriam DeBruyne, Rebecca Y. Broadhurst, and Tilar Martin for technical support; Dr. Jeffrey Zigman for providing the HDC-cre mice and Dr. Yuchio Yanagawa for providing the GAD67 flox-flox mice. ited (Scammell et al., 2019). In general support of this hypothesis, anti-histaminergic drugs are often used as an over-the-counter treatment for insomnia (Krystal et al., 2013), whereas pitolisant, an inverse agonist at the $\mathrm{H} 3$-receptor (an inhibitory autoreceptor on histamine neurons; De Luca et al., 2016), has shown promising efficacy in reducing hypersomnolence and cataplexy in patients with narcolepsy (Lin et al., 2008; Dauvilliers et al., 2013;

\footnotetext{
The authors declare no competing financial interests.

*A.V. and T.M. contributed equally to this work.

Correspondence should be addressed to Patrick M. Fuller at pfuller@bidmc.harvard.edu.

https://doi.org/10.1523/JNEUROSCI.1032-19.2019

Copyright $\odot 2019$ the authors
} 
Szakacs et al., 2017). TMN histamine neurons also fire in a statedependent manner, exhibiting maximum firing rates during waking (Takahashi et al., 2006), and CSF histamine levels are similarly highest during waking (Mochizuki et al., 1991). These wake-active histamine neurons are also reciprocally connected with the sleeppromoting ventrolateral preoptic (VLPO) nucleus (Chou et al., 2002; Sherin et al., 1996, 1998; Zhang et al., 2015; Chung et al., 2017; Kroeger et al., 2018), and it has been shown that histamine release from TMN axon terminals can inhibit putative sleeppromoting neurons in the VLPO through increased GABAergic tone, although this effect is likely indirect (Williams et al., 2014). Additional support for a role of TMN histamine neurons in arousal comes from more recent studies showing that chemogenetic activation of TMN histamine neurons increases locomotor activity in an open-field challenge (Yu et al., 2015), whereas acute optogenetic inhibition of ventral TMN histamine neurons can induce slow-wave sleep (Fujita et al., 2017).

Unexpectedly, however, cell-body-specific lesions placed in the TMN produce limited alterations in sleep or wake in rats (Denoyer et al., 1991; Gerashchenko et al., 2004; Blanco-Centurion et al., 2007). In addition, transgenic mice in which histidine decarboxylase (HDC; an obligate enzyme that converts L-histidine to histamine) expression is disrupted exhibit only modest changes in overall wakefulness (Parmentier et al., 2002; Anaclet et al., 2009), although they show less wakefulness following a behavioral challenge, such as a cage change (Parmentier et al., 2002). Conversely, transgenic mice bearing a $\mathrm{GABA}_{\mathrm{A}}$ receptor loss-of-function mutation on HDC neurons, which results in increased HDC neuron excitability, exhibit higher arousal following a cage change (Zecharia et al., 2012). In light of the foregoing evidence, the role of histamine in regulating arousal remains unclear.

TMN histamine neurons also contain GABA and express the GABA synthetic enzyme glutamic acid decarboxylase (GAD) 67 (Takeda et al., 1984; Senba et al., 1985; Airaksinen et al., 1992). It is thought that GABA transmission from TMN histamine neurons may also regulate arousal because siRNA-mediated knockdown of the vesicular GABA transporter (VGAT; which is required for packaging GABA into synaptic vesicles for release) selectively in histamine neurons produces sustained wakefulness and hyperactivity in mice (Yu et al., 2015). Here, we sought to determine the effects of chronic disruption of GABA synthesis and transmission by TMN histamine neurons on overall arousal and sleep-wake amounts. We then used genetically targeted activation and inhibition of TMN ${ }^{\mathrm{HDC}}$ neurons to more definitively assess their contribution to the initiation and maintenance of electroencephalographic (EEG) and behavioral arousal.

\section{Materials and Methods}

\section{Animals}

All animal experiments and procedures on mice were approved by the Institutional Animal Care and Use Committee of Beth Israel Deaconess Medical Center. Mice were maintained on a $12 \mathrm{~h}$ light/dark cycle (lights on at 7:00 A.M. $)$ in constant temperature $\left(22 \pm 1^{\circ} \mathrm{C}\right)$ and humidity with ad libitum access to food and water throughout the study.

Adult male HDC-cre mice (Yanovsky et al., 2012; Walker et al., 2013) and HDC-cre mice crossed with GAD67flox-flox (Obata et al., 2008), VGAT flox-flox (Tong et al., 2008), hM3Dq-mCitrine $e^{l o x-S T O P-l o x}$ (Zhu et al., 2016), and

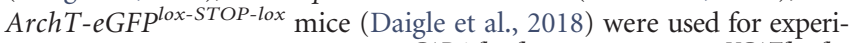
ments. For experiments using $H D C^{G A D 67 f l o x-f l o x}$ mice and $H D C^{V G A T f l o x-f l o x}$ mice, littermates that did not express cre were used as controls. For experiments using HDC ${ }^{\text {ArchT-eGFP }}$ mice, littermates that did not express ArchT-eGFP (i.e., mice negative for either HDC-cre or the ArchT-eGFP ${ }^{l o x-S T O P-l o x}$ gene) were used as controls.

\section{Surgery}

Stereotaxic injections. Mice were anesthetized with ketamine/xylazine (100 and $10 \mathrm{mg} / \mathrm{kg}$, respectively, i.p.), received $4 \mathrm{mg} / \mathrm{kg}$ meloxicam SR subcutaneously for analgesia and the surgical area (top of the skull) was shaved in preparation for surgery. The mouse was then secured into a stereotaxic frame and the skin over the top of the skull sterilized with betadine and 70\% isopropyl ethanol before an incision was made down the midline of the skull, exposing lambda and bregma. Burr holes $(0.7$ $\mathrm{mm}$ diameter) were drilled immediately above the TMN and an incision made in the meningeal layer with a $25 \mathrm{G}$ needle. To selectively express hM3Dq in TMN ${ }^{\mathrm{HDC}}$ neurons, we injected $\sim 60 \mathrm{nl}$ of an adeno-associated viral (AAV) vector expressing the hM3Dq-mCherry receptor (hSyn-DIOhM3Dq-mCherry-AAV10, packaged as described previously (Venner et al., 2016)) bilaterally into the TMN [anteroposterior (AP) $=-1.9 \mathrm{~mm}$ from Bregma; lateral $(\mathrm{ML})= \pm 1.0 \mathrm{~mm}$; dorsoventral $(\mathrm{DV})=-5.0 \mathrm{~mm}$ as per the mouse atlas of Paxinos and Franklin (2001)] using a compressed air delivery system (adapted from Amaral and Price, 1983) to expel small volumes of the viral vector into the parenchyma $(0.5 \mathrm{nl}$ per puff at a pressure of $\sim 30 \mathrm{psi}$ ). The compressed air delivery system consisted of a regulated air supply (Linde Medical Gas UN 1002, with Western Digital M1-346-PG regulator) connected to the input port of a solenoid (Clippard, CR-EV-3-24-L). The output port of the solenoid was directly attached, via 1/16 inch internal diameter PVC tubing, to a small diameter micropipette $(0.275 \mathrm{~mm}$ internal diameter, P-.275M-1M-1-12, Wilmad LabGlass), pulled such that it gradually tapered a to $10-20 \mu \mathrm{m}$ diameter opening. The micropipette was filled with the viral vector and the timing of each puff was controlled by a Grass S44 stimulator to trigger the solenoid at a rate of $\sim 0.8-1 \mathrm{~Hz}$. Following the intracranial injection, we waited for $3 \mathrm{~min}$ to allow the viral vector to disperse before gently withdrawing the micropipette from the brain. The scalp wound was closed with surgical sutures, $0.5 \mathrm{ml}$ saline was administered subcutaneously, and the mouse allowed to regain consciousness on a heating pad.

$E E G / E M G$ and optical fiber implants. All mice underwent a surgery to implant a headstage for recording the EEG and electromyogram (EMG). The headstage consisted of a six pin connector (Heilind Electronics, catalog \#MMX853-43-006-10-001000) soldered to four EEG screws (Pinnacle, catalog \#8403) and two flexible EMG wire electrodes (Plastics One, catalog \#E363). Mice were prepared for surgery as described in the Stereotaxic injections section and four burr holes $(0.7 \mathrm{~mm}$ diameter $)$ were drilled in the skull: two anterior burr holes were drilled at AP: $+1.0 \mathrm{~mm}$ and ML: $\pm 1.0 \mathrm{~mm}$ and two posterior burr holes were drilled at AP: -2.0 and ML: \pm 1.0 . The EEG electrode screws were inserted into the burr holes and affixed to the skull with a layer of dental cement mixed with cyanoacrylate glue. The EMG electrodes were guided down the back of the neck underneath the trapezius muscles. The whole assembly was coated in a layer of dental cement to provide insulation and structural stability. The mice recovered for an additional 2 weeks following implantation of the EEG/EMG connector. For mice that received optogenetic stimulation of the TMN, the electrodes were implanted at AP: $+1.5 \mathrm{~mm}$ (anterior), AP: -1.5 (posterior), and ML: $\pm 1.0 \mathrm{~mm}$ to allow placement of optical fibers over the $\mathrm{TMN}(\mathrm{AP}=-1.9 \mathrm{~mm} ; \mathrm{ML}= \pm 1.0 \mathrm{~mm} ; \mathrm{DV}=$ $-4.8 \mathrm{~mm}$ ). The in-house manufactured optical fibers, comprised a fiber optic cable (200 $\mu$ m outer diameter; Thorlabs, FT200EMT) inserted into a ceramic ferrule (200 $\mu \mathrm{m}$ internal diameter; Thorlabs, CFLC230-10), and epoxied into place (PFP 353ND, Precision Fiber Products). At the mating end of the ferrule, the optical fiber was flat cleaved and polished and at the other end, the optical fiber was cut to size $(5.5 \mathrm{~mm})$. After positioning of the EEG/EMG headset, each optical fiber was stereotaxically guided into position and glued into place using a mixture of dental cement and cyanoacrylate glue, before the entire assembly was coated in a layer of dental cement.

\section{Sleep-wake monitoring}

After recovery from surgery, the mice were housed individually in transparent barrels in an insulated, sound-proofed recording chamber. Mice were habituated to the recording cable for $4-5 \mathrm{~d}$ before commencing polygraphic recordings. Cortical EEG (ipsilateral frontoparietal leads) and EMG signals were amplified $\times 5000$ (AM Systems, Model 3600) and 
digitized with a resolution of $500 \mathrm{~Hz}$ using either Vital recorder (Kissei, Comtec) or a Micro 1401-3 (Cambridge Electronic Design).

\section{Chemogenetic experiments}

For chemogenetic experiments, mice were recorded for $24 \mathrm{~h}$ baseline periods followed by injections of clozapine- $\mathrm{N}$-oxide (CNO; NIMH Chemical Synthesis and Drug Supply Program; $0.3 \mathrm{mg} / \mathrm{kg}$ in saline, i.p.) at 10:00 A.M. (ZT3; light period, time of high sleeping drive). As an injection control, the same mice were injected with saline at 10:00 A.M.. Mice bearing chemogenetic receptors also underwent a cage change challenge. At 1:00 P.M. (ZT6; the middle of the inactive period), mice were injected with $\mathrm{CNO}$ and placed into a cage with clean bedding that was otherwise identical to the home cage. The cage change was also performed on the same mice following a ZT6 saline injection, as an injection control. All CNO and saline injections were performed in a random sequence and separated by $2 \mathrm{~d}$ washout periods.

\section{Optogenetic experiments}

For optogenetic experiments, mice were habituated to both the EEG/ EMG recording cable and optical patch cables for at least $3 \mathrm{~d}$ before beginning recordings. Experiments were performed between ZT11 and ZT14 (a period of high activity in nocturnal mice). We modified an open-source Online Sleep Detection script [Spike 2, Cambridge Electronic Design (CED); source code available from the manufacturer's website] to detect when mice had been in active wake for at least $2 \mathrm{~min}$, before delivering a $5 \mathrm{~min}$ duration, $15 \mathrm{~mW}, 589 \mathrm{~nm}$ continuous light pulse bilaterally to TMN ${ }^{\mathrm{HDC}}$ neurons (R580503GX, LaserGlow) using an optical splitter (DMC_1x2i_VIS_FC, Doric) and custom-made patch cables. Each mouse received one stimulation per night and the experiment was repeated on an additional two evenings, at least $3 \mathrm{~d}$ apart.

\section{Sleep scoring and analysis}

Using SleepSign for Animal (Kissei, Contec) or Spike 2 (CED), polygraphic records were visually scored in $10 \mathrm{~s}$ epochs for wakefulness, rapid eye movement (REM) sleep, and non-REM (NREM) sleep. The percentage of time spent in wake, NREM sleep and REM sleep were summarized for each group and each condition.

For EEG power spectrum analysis, recordings were scored again in $5 \mathrm{~s}$ epochs and epochs containing artifacts occurring during active wake (with large movements) or containing mixed vigilance states were visually identified and omitted from the spectral analysis. EEG power spectra were computed using a fast Fourier transform routine (FFT) for consecutive $5 \mathrm{~s}$ epochs within the frequency range of $0.5-200 \mathrm{~Hz}$, with a large notch filter applied between 50 and $70 \mathrm{~Hz}$, and binned in $0.5 \mathrm{~Hz}$ increments. To determine the effect of CNO injection on sleep-wake power spectra in $\mathrm{TMN}^{\mathrm{HDC}} \mathrm{hM} 3 \mathrm{Dq}$ receptor-expressing mice, the EEG power spectra were analyzed for a $2 \mathrm{~h}$ period between 1 and $3 \mathrm{~h}$ after injection of vehicle or CNO. The spectrogram for each vigilance state was averaged and processed as a percentage of the baseline condition (i.e., the spectrogram from the same mouse at the same time of day). To determine the effect of optogenetically inhibiting $\mathrm{TMN}^{\mathrm{HDC}}$ neurons upon the EEG spectra, the average spectrogram during the 5 min optogenetic stimulation was expressed as a percentage of the average spectrogram calculated 5 min immediately preceding the light pulse. Relative power bins were summed as such: $\delta, 0.5-4 \mathrm{~Hz}$; low $\theta, 4-6 \mathrm{~Hz}$; high $\theta, 6-10 ; \alpha, 10-20 \mathrm{~Hz}$; $\beta, 20-50 \mathrm{~Hz} ; \gamma, 70-200 \mathrm{~Hz}$. The data were visualized using a custom written Python script (http://www.python.org) and Prism v6 (GraphPad Software).

\section{In vitro electrophysiological recordings}

$\mathrm{HDC}^{\text {ArchT-eGFP }}$ mice $(n=3)$ were used for in vitro electrophysiological recordings. The mice were deeply anesthetized with isoflurane $(5 \%$ in oxygen) for $\sim 3-4 \mathrm{~min}$ and then transcardially perfused with ice-cold $\mathrm{N}$-methyl-D-glucamin-(NMDG)-based solution containing the following (in mM): $100 \mathrm{NMDG}, 2.5 \mathrm{KCl}, 1.24 \mathrm{NaH}_{2} \mathrm{PO}_{4}, 30 \mathrm{NaHCO}_{3}, 25$ glucose, $20 \mathrm{HEPES}, 2$ thiourea, $5 \mathrm{Na}$-L-ascorbate, $3 \mathrm{Na}$-pyruvate, $0.5 \mathrm{CaCl}_{2}$, $10 \mathrm{MgSO}_{4}$ ( $\mathrm{pH} 7.3$ with $\mathrm{HCl}$ when carbogenated with $95 \% \mathrm{O}_{2}$ and $5 \%$ $\left.\mathrm{CO}_{2} ; 310-320 \mathrm{mOsm}\right)$. The brains were immediately removed and 250$\mu \mathrm{m}$-thick coronal slices were made by sectioning in ice-cold NMDGbased ACSF using a vibrating microtome (VT1200S, Leica). The slices were incubated in NMDG-based ACSF for $5 \mathrm{~min}$ at $37^{\circ} \mathrm{C}$ and then for 10 min in normal ACSF (Na-based solution; $37^{\circ} \mathrm{C}$ ). Normal ACSF (Nabased solution) contained the following (in $\mathrm{mM}$ ): $120 \mathrm{NaCl}, 2.5 \mathrm{KCl}, 1.3$ $\mathrm{MgCl}_{2}, 10$ glucose, $26 \mathrm{NaHCO}_{3}, 1.24 \mathrm{NaH}_{2} \mathrm{PO}_{4}, 4 \mathrm{CaCl}_{2}, 2$ thiourea, 1 Na-L-ascorbate, 3 Na-pyruvate ( $\mathrm{pH}$ 7.3-7.4 when carbogenated with $95 \% \mathrm{O}_{2}$ and $\left.5 \% \mathrm{CO}_{2} ; 310-320 \mathrm{mOsm}\right)$. After incubation, the slices were allowed to gradually reach room temperature $\left(22^{\circ} \mathrm{C}\right)$ before starting recordings. TMN-containing slices were placed into a recording chamber and perfused $(2 \mathrm{ml} / \mathrm{min})$ with normal ACSF. HDC ${ }^{\text {ArchT-eGFP }}$ neurons in the TMN were identified using a combination of fluorescence and infrared differential interference contrast (IR-DIC) microscopy, using a fixed stage upright microscope (BX51WI, Olympus America), equipped with a Nomarski water-immersion lens (Olympus $40 \times / 0.8 \mathrm{NAW}$ ) and IRsensitive CCD camera (ORCA-ER, Hamamatsu). Real-time images were acquired using MATLAB (MathWorks) script software. Recordings were made using a K-gluconate-based pipette solution, which contained the following (in $\mathrm{mm}$ ): $120 \mathrm{~K}$-Gluconate, $10 \mathrm{KCl}, 3 \mathrm{MgCl} 2,10 \mathrm{HEPES}, 2.5$ K-ATP, $0.5 \mathrm{Na}-\mathrm{GTP}$ ( pH 7.2 adjusted with $\mathrm{KOH} ; 280 \mathrm{mOsm}$ ). Neurons were recorded in whole-cell configuration using a MultiClamp 700B amplifier, a Digidata 1322A interface, and Clampex 9.0 software (Molecular Devices). Neurons showing changes in input resistance $>10 \%$ were excluded from the analysis. HDC ${ }^{\text {ArchT-eGFP }}$ neurons were photo-inhibited using full-field light openings ( $\sim 1 \mathrm{~mW} / \mathrm{mm}^{2}, 1 \mathrm{~mm}$ beam width) from a LUXEON light-emitting diode (589 nm wavelength; Thorlabs, M565L3) coupled to the epifluorescence pathway of microscope. In vitro recording data were analyzed using Clampfit 10 (Molecular Devices), MiniAnalysis 6 software (Synaptosoft), and Prism 7 (GraphPad). Figures were generated using Igor Pro 6 (WaveMetrics), Photoshop (Adobe) software, and MATLAB (MathWorks) software. Only neurons spontaneously firing were considered for analysis. Firing frequency and membrane potential changes were calculated by comparing values before and during orange light stimulation.

\section{Immunohistochemistry}

Mice received intraperitoneal injections of either saline or CNO $(0.3 \mathrm{mg} /$ $\mathrm{kg}$ ) at ZT3 and $2 \mathrm{~h}$ later were killed by deep anesthesia with $200 \mathrm{mg} / \mathrm{kg}$ of chloral hydrate, before being transcardially perfused with $20 \mathrm{ml}$ saline, followed by $100 \mathrm{ml}$ of neutral phosphate buffered formalin (4\%, Fischer Scientific). Brains were removed, incubated in $20 \%$ sucrose at $4^{\circ} \mathrm{C}$ until they sank, and then sectioned at $40 \mu \mathrm{m}$ on a freezing microtome in three series. Sections were washed in PBS, and incubated in primary antiserum [dsRed (1:10K), c-Fos (1:20,000), GFP (1:10,000), HDC (1:1000), or HA-tag (1:500); See also Antibody characterization] diluted in PBS containing $0.3 \%$ Triton X-100 (PBST) and $0.2 \%$ sodium azide for $1 \mathrm{~d}$ at room temperature. For chromogenic detection of primary antibodies, sections were then washed in PBS and incubated in biotinylated secondary antiserum (against appropriate species IgG, 1:1000; Jackson ImmunoResearch) in PBST for $2 \mathrm{~h}$, washed in PBS and incubated in ABC reagents (Vectastain, Vector Laboratories) in PBST for $1 \mathrm{~h}$. Sections were then washed again and incubated in a solution of $0.02 \% 3,3$-diaminobenzidine tetrahydrochloride (DAB; Sigma-Aldrich) and $0.009 \% \mathrm{H}_{2} \mathrm{O}_{2}$. The sections were stained brown with DAB or black (c-Fos) by DAB plus $0.005 \%$ cobalt chloride and $0.01 \%$ nickel ammonium sulfate For fluorescent detection of primary antibodies, sections were washed three times in PBS and incubated in fluorescent secondary antiserum for $2 \mathrm{~h}$ (against appropriate species IgG, 1:500; Jackson ImmunoResearch). Sections were then washed twice in PBS before mounting on positive charged slides (Denville Scientific) and imaged on an Olympus BX61VS slide scanner.

Green fluorescent images were false-colored to cyan using the LUT function in FIJI (ImageJ) for the benefit of the red-green color blind population.

\section{Antibody characterization}

The rabbit polyclonal antibody against GFP was raised against GFP isolated directly from the jellyfish Aequorea Victoria (Invitrogen, A6455). This antibody also recognizes both eYFP and mCitrine protein and its specificity of immunostaining was confirmed by lack of detectable immunostaining in uninjected mice. 
The rabbit polyclonal antibody against mCherry was raised against dsRed (Clontech; catalog \#632496) and the specificity of immunostaining for dsRed was indicated by the lack of detectable immunostaining in uninjected mice.

The guinea pig polyclonal antibody against HDC was raised against recombinant HDC product produced in E.coli (American Research Product, catalog \#03-16046). HDC staining at the concentration used was not observed outside of the TMN.

The rabbit monoclonal antibody was raised against the influenza hemagglutinin epitope (YPYDVPDYA) in animals (Cell Signaling Technology, 3724P). Specificity of immunostaining was confirmed by lack of detectable immunostaining in mice not expressing the HA-tag.

For all secondary antibody immunohistochemical controls, the primary antibodies were omitted and the tissue showed no immunoreactivity above background.

\section{In situ hybridization}

Mice were killed by an overdose of chloral hydrate $(200 \mathrm{mg} / \mathrm{kg})$ and transcardially perfused with $20 \mathrm{ml}$ saline followed by $100 \mathrm{ml}$ formalin $(10 \%)$. The brains were removed from the skull and incubated in RNAase free $20 \%$ sucrose solution until they sank. The brain was then sectioned under RNA-ase free conditions on a freezing microtome in $4 \times 30$ $\mu \mathrm{m}$ series, collected into RNA-ase free PBS-Az before being transferred into RNA-later (Thermo Fisher) and stored at $-20^{\circ} \mathrm{C}$ (if not used immediately). Free-floating sections were incubated overnight at $53^{\circ} \mathrm{C}$ in hybridization buffer and DIG-labeled probes against GAD67 or VGAT (Burgess et al., 2013; Geerling et al., 2017). The next day, the sections were rinsed in $2 \times$ standard saline citrate with $50 \%$ formamide $(2 \times 1 \mathrm{~h})$ and in $1 \times$ standard saline citrate with $50 \%$ formamide $(3 \times 1 \mathrm{~h})$ at $53^{\circ}$. The sections were then washed in Tris-buffered, $\mathrm{pH} 7.5$, PBS $(3 \times 10$ $\min$ ) and incubated overnight in peroxidase-conjugated anti-DIG primary antibody (1:500; Roche, catalog \#11 207733 910) with 1\% blocking reagent (Roche, catalog \#11 096176001 ). The next day, the sections were washed and incubated for 10-15 min in TSA Plus Cy3 (PerkinElmer, NEK 744001KT). The sections were then immunolabeled for HDC or GFP (as described in the Immunohistochemistry section), mounted on positively charged slides, and imaged using a Zeiss LSM 9 confocal microscope.

\section{Statistical analysis}

Statistical analysis was performed using Prism v6 (GraphPad Software). A repeated-measures two-way ANOVA followed by a post hoc Sidak test or paired $t$ test was used to compare the effects of the CNO injection on sleep-wake parameters, in a within-subject controlled design. A betweensubjects controlled design was used to assess the effect of both GAD67 and VGAT knock-out, and HDC ${ }^{\text {ArchT }}$ inhibition on sleep-wake. Two-way ANOVA followed by Sidak post hoc tests, or independent sample $t$ tests, were used for statistical comparisons. For statistical analysis of in vitro electrophysiology data, mean membrane potential and firing frequency were compared using a paired $t$ test before and during the 1 min orange light pulse. Values showing $p<0.05$ were considered significant. Sample size and power calculations were performed post hoc using PS Power and Sample Size Calculations by William D. DuPont and Walton D. Plummer (http://biostat.mc.vanderbilt.edu/PowerSampleSize) using mean and SD derived from our analysis. The present study was sufficiently powered to detect effect sizes.

\section{Results}

To investigate the role of GABA transmission from $\mathrm{TMN}^{\mathrm{HDC}}$ neurons in arousal, we first generated a knock-out mouse model in which GABA is depleted through genetic deletion of GAD67 (the GABA synthesis enzyme, which is abundantly expressed in $\mathrm{TMN}^{\mathrm{HDC}}$ neurons) selectively in TMN histamine neurons. To do so, we crossed GAD67 flox-flox mice (Obata et al., 2008) with HDCcre mice (henceforth $H D C^{\text {GAD67flox-flox }}$; Fig. $1 A, B$ ) and performed polysomnographic recordings in these mice to record sleep-wake behavior. Following the cross, GAD67 was absent from about half the $\mathrm{TMN}^{\mathrm{HDC}}$ population (GAD67 is expressed in $52.3 \pm 5.4 \%$
$\mathrm{TMN}^{\mathrm{HDC}}$ neurons in the HDC $\mathrm{CAD}^{\text {GAflox-flox }}(n=2$ mice) compared with GAD67 expression in $85.9 \pm 2.6 \%$ of TMN ${ }^{\mathrm{HDC}}$ neurons in littermate controls $(n=2$ mice, $p=0.003$, independent sample $t$ test), indicating significant but also incomplete depletion of GAD67 in TMN ${ }^{\text {HDC }}$ neurons. We found that there was little difference in hourly amounts of wake, NREM sleep or REM sleep, over the $24 \mathrm{~h}$ day, compared with littermate controls (Fig. $1 C)$.

Although the foregoing results were surprising, $H D C^{\text {GAD67flox-flox }}$ mice may still possess the capacity to synthesize GABA. We therefore crossed HDC-cre mice with VGA $T^{\text {flox-flox }}$ mice (Tong et al., 2008), yielding a mouse model in which $\mathrm{TMN}^{\mathrm{HDC}}$ neurons are unable to release GABA synaptically (Fig. $1 D$; henceforth $\left.H D C^{V G A T f l o x-f l o x}\right) . H D C^{V G A T f l o x-f l o x}$ mice showed normal hourly amounts of sleep and wake compared with littermate controls (HDC $C^{\text {VGATflox-flox }}$ mice $n=12$; control $n=8$; Fig. $1 E$ ). Given this surprising outcome, we asked whether the absence of phenotype was linked with incomplete recombination of the floxed VGAT allele in $\mathrm{TMN}^{\mathrm{HDC}}$ neurons. Using combined immunohistochemistry for HDC and in situ hybridization for the deleted exon 2 of the VGAT gene, we confirmed the absence of VGAT expression in $\mathrm{TMN}^{\mathrm{HDC}}$ neurons in the HDC ${ }^{V G A T f l o x-f l o x}$ mice. Unexpectedly, however, VGAT and HDC were coexpressed only in a very small fraction of TMN ${ }^{\mathrm{HDC}}$ neurons in littermate controls $\left(7.11 \pm 2.05 \%\right.$ of ventral TMN ${ }^{\mathrm{HDC}}$ neurons expressed VGAT; Fig. $1 F$ ), indicating that VGAT is not typically expressed in TMNHDC neurons. This finding suggests that HDC neurons may not require VGAT to release GABA and could explain why sleepwake quantities were not appreciably altered in $H D C^{V G A T f l o x-f l o x}$ mice.

We next asked whether acute and selective chemogenetic activation (Armbruster et al., 2007) of TMN ${ }^{\text {HDC }}$ neurons in adult mice could influence sleep and wakefulness. To do this, we placed bilateral injections of hM3Dq-mCherry-AAV into the TMN of HDC-cre mice (hM3Dq-mCherry was expressed in $47.3 \pm 4.1 \%$ of TMN ${ }^{\mathrm{HDC}}$ neurons $(n=8$ mice $\left.)\right)$ and administered the chemogenetic ligand, $\mathrm{CNO}\left(0.3 \mathrm{mg} \mathrm{kg}^{-1}\right.$, i.p., which is a concentration that robustly activates TMN ${ }^{\mathrm{HDC}}$ neurons as determined by activation of cFos; $27.30 \pm 7.55 \%$ hM3Dq-expressing TMN ${ }^{\mathrm{HDC}}$ neurons expressed cFos following a saline injection $(n=4$ mice) versus $68.88 \pm 4.17 \%$ following CNO injection $(n=10$ mice), $p=0.0002$, independent sample $t$ test). At ZT3 (Fig. $2 A-C$ ), a time of day at which sleep pressure is high, activation of TMN ${ }^{\mathrm{HDC}}$ neurons did not alter sleep architecture or EEG spectra of any arousal state (Fig. 2D-G).

It has however been reported that the characteristic increase in arousal following a cage change is absent in HDC knock-out mice (Parmentier et al., 2002), but is enhanced in mice bearing a lossof-function mutation of $\mathrm{GABA}_{\mathrm{A}}$ receptors selectively in histamine neurons (Zecharia et al., 2012). We therefore asked whether acute activation of TMN ${ }^{\mathrm{HDC}}$ neurons would affect the arousal response to a clean cage change challenge during the middle of the day (ZT6). We found that administration of CNO, increased wakefulness in mice for $2-3 \mathrm{~h}$ after the cage change, compared with the control saline injection (Fig. $2 \mathrm{H}$ ).

As our transfection rates were moderate, we next crossed HDC-cre mice to hM3Dq-mCitrine $e^{\text {lox-STOP-lox }}$ mice (Zhu et al., 2016; Fig. 3A) which yielded far better penetrance of hM3Dq expression in the TMN ${ }^{\mathrm{HDC}}$ population $\left(H D C^{h M 3 D q}\right.$; Fig. $\left.3 B\right)$. Using this mouse line, hM3Dq was expressed in $84.5 \pm 6.1 \%$ of $\mathrm{TMN}^{\mathrm{HDC}}$ neurons $(n=2$ mice) and we confirmed CNO activation of these neurons by cFos expression $\left[24.38 \pm 9.24 \% \mathrm{HDC}^{\mathrm{hM} 3 \mathrm{Dq}}\right.$ neurons expressed cFos following a saline injection $(n=3$ mice) 
A

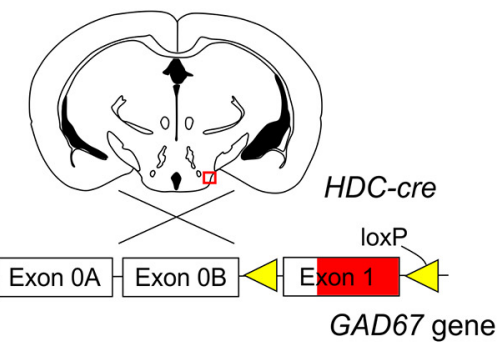

B1

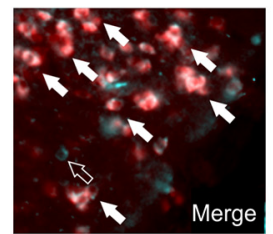

B2

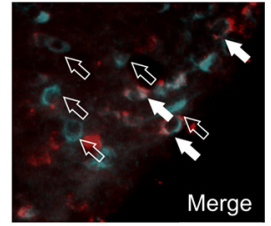

NREM
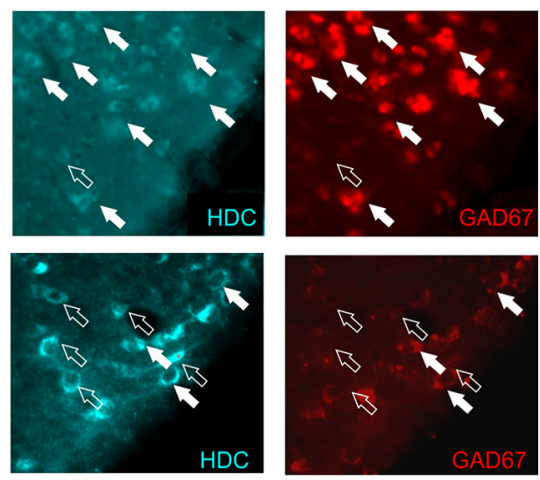

REM
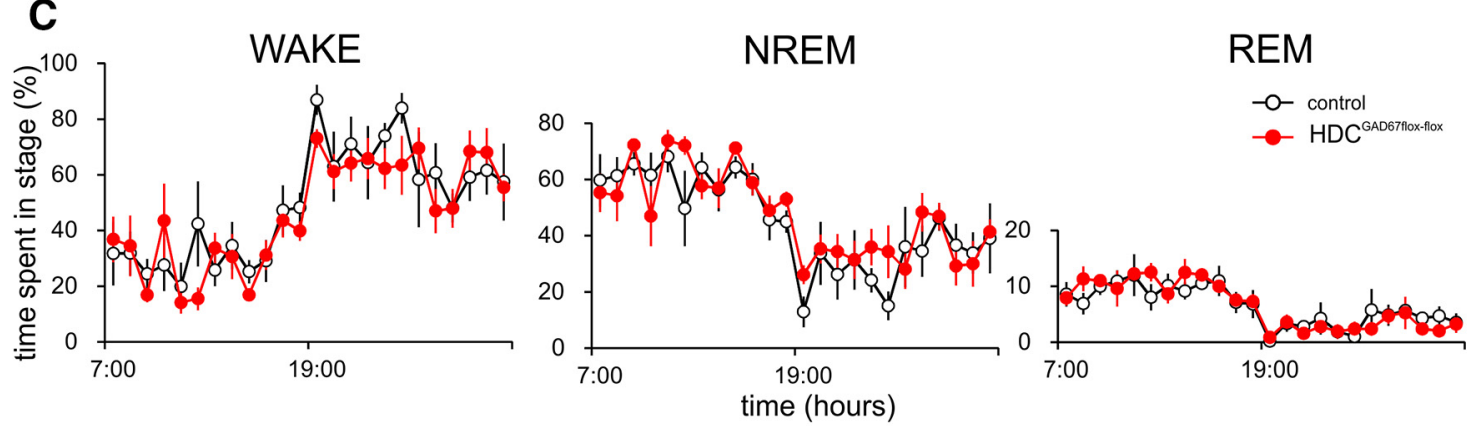

D
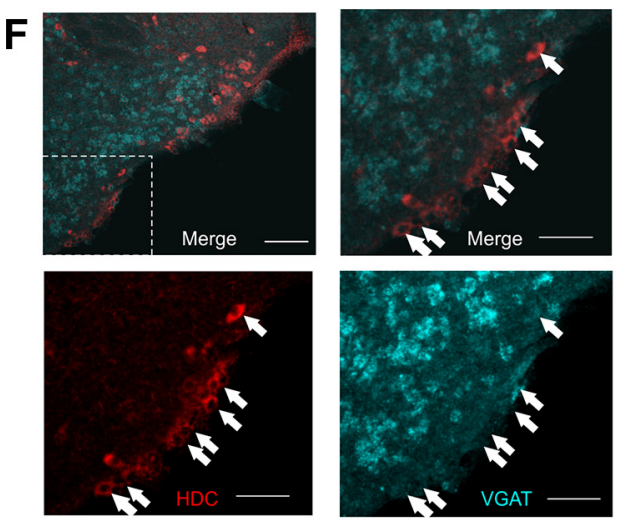

E

NREM

REM
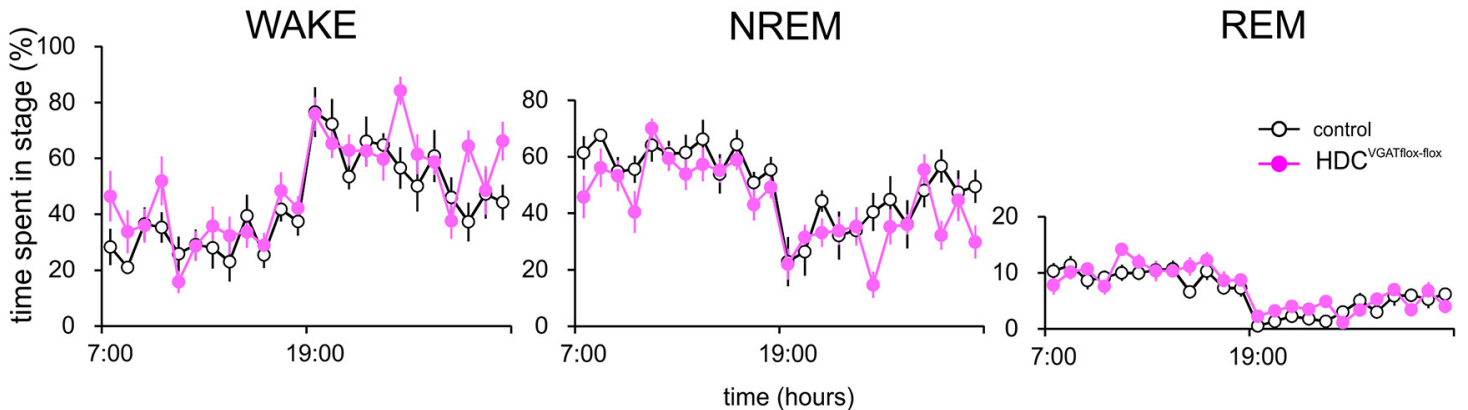

Figure 1. Genetic deletion of GAD67 or VGAT from TMN ${ }^{H D C}$ neurons does not alter sleep-wake in mice. $\boldsymbol{A}$, Schematic of the genetic cross used to generate $H D C C^{G A D 67 f l o x-f l o x}$ mice. $\boldsymbol{B}$, Photomicrograph illustrating coexpression (white) of HDC IR (cyan) and GAD67 mRNA (red), in the ventral TMN in a control mouse (B1) and in a HDC ${ }^{\text {GAD67flox-flox }}$ mouse in which GAD67 is floxed out of HDC-containing neurons (B2). The majority of TMN ${ }^{\text {HDC }}$ neurons express GAD67 (closed arrows) in the control condition, whereas GAD67 is noticeably absent in a high proportion of TMN ${ }^{\mathrm{HDC}}$ neurons in the floxed condition. Open arrows indicate TMN ${ }^{H D C}$ neurons that do not express GAD67. C, Hourly mean ( \pm SEM) amounts of wake, NREM sleep, and REM sleep in HDC ${ }^{6 A D 67 f l o x-f l o x}$ mice (red) and littermate controls (black), over a $24 \mathrm{~h}$ day. $\boldsymbol{D}$, Schematic of the genetic cross used to generate HDC VGATflox-flox mice. $\boldsymbol{E}$, Hourly mean ( \pm SEM) amounts of wake, NREM sleep, and REM sleep in HDC VGAFflox-flox mice (pink) and littermate controls (black), over a $24 \mathrm{~h}$ day. $\boldsymbol{F}$, Top left, Photomicrograph illustrating a conspicuous lack of coexpression of HDC IR (red) with VGAT mRNA (cyan), in the ventral TMN. Scale bar, $100 \mu \mathrm{m}$. The white boxed area is shown at higher magnification (top right) and in split color channels (bottom). Arrows indicate TMN HDC neurons that do not contain VGAT. Scale bar, $50 \mu \mathrm{m}$.

vs $74.0 \pm 7.4 \%$ following CNO injection ( $n=3$ mice), $p=0.014$, independent sample $t$ test]. Administration of CNO still had no effect on sleep-wake quantities (compared with saline injections in the same mice; Fig. 3C) but reduced EEG spectral power in the high gamma range in wake and NREM sleep and increased theta power during REM sleep (Fig. $3 D$ ). Activation of TMN ${ }^{\mathrm{HDC}}$ neurons had no effect on the number or duration of wake or NREM sleep episodes (Fig. $3 E, F$ ), whereas the number of entries into 

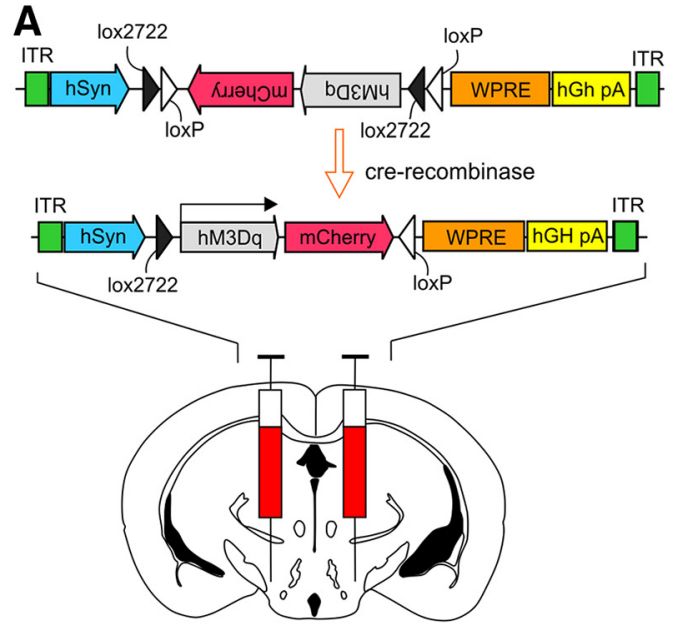

D
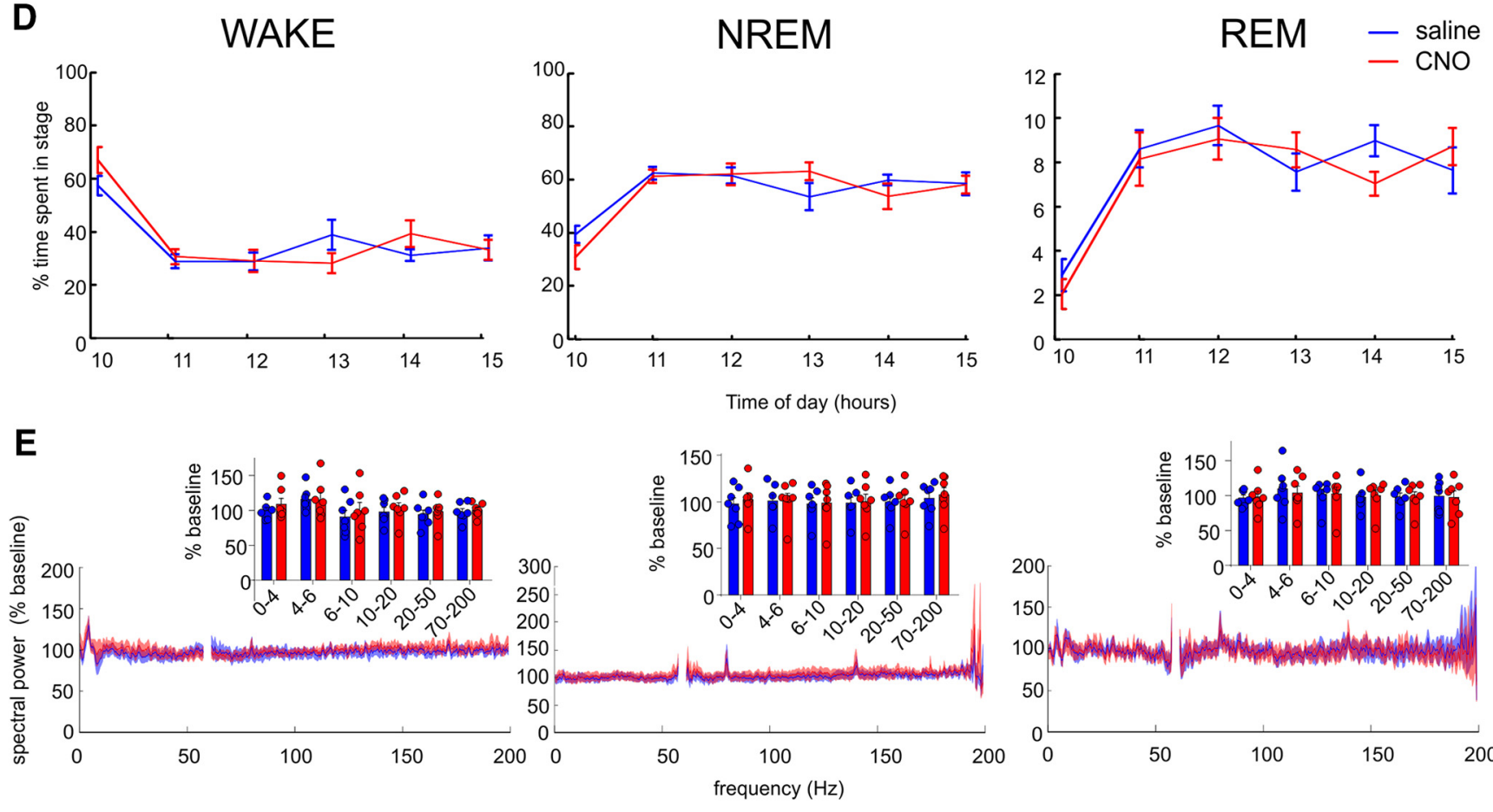

B hM3Dq-mCherry cFos

C
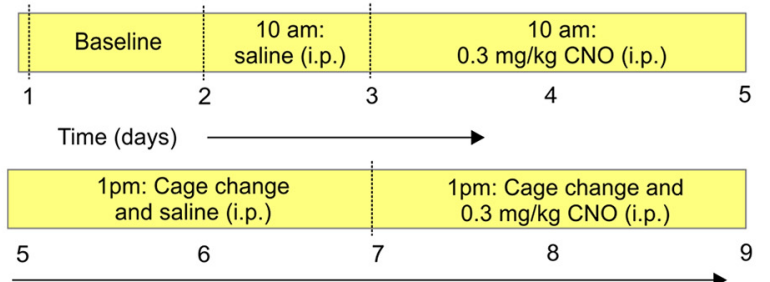

$\mathbf{F}$

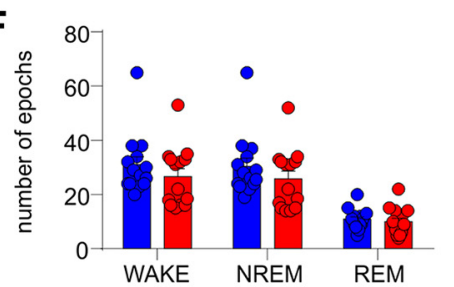

G

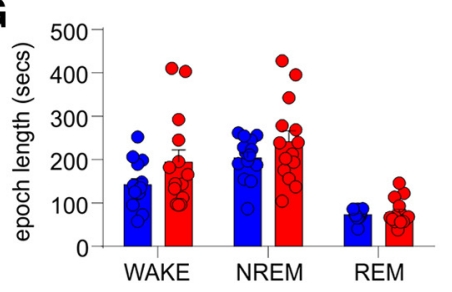

H
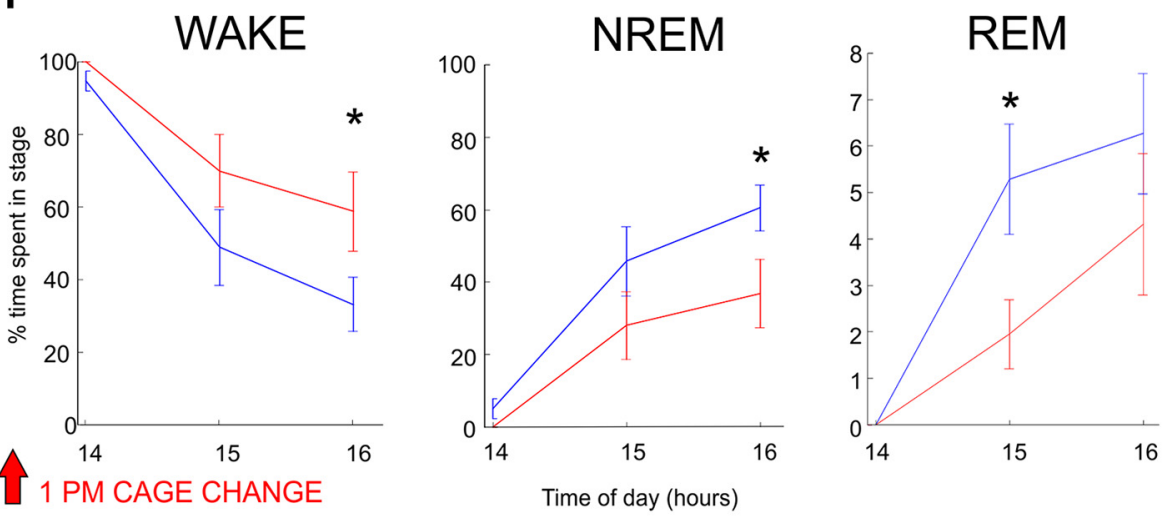

Figure 2. Chemogenetic activation of TMN ${ }^{\mathrm{HDC}}$ neurons, using a viral vector-based expression approach, does not enhance arousal under baseline conditions but increases wakefulness following a clean cage change challenge. $\boldsymbol{A}$, Experimental schematic: AAV-hM3Dq-mCherry was injected bilaterally into the TMN of HDC-cre mice. $\boldsymbol{B}$, Photomicrograph illustrating hM3Dq-mCherry (dsRed IR; brown) and (Fos IR (black) in the ventral TMN. High magnification of the black box is shown on the right. Scale bar, $100 \mu$ m. C, Experimental timeline. D, Hourly mean ( \pm SEM) amounts of wake, NREM sleep and REM sleep in $H D C^{h M 3 D q}$ mice following ZT3 saline (blue) and CNO (red) injection ( $n=14$, two-way RM ANOVA followed by Sidak post hoc test). $E$, FFT of EEG spectrogram during wake, NREM sleep and REM sleep following ZT3 saline (blue) or CNO (red) injection in HDC ${ }^{\mathrm{M} 3 D q}$ mice. Insets show mean spectral power ( $n=7$, two-way RM ANOVA followed by (Figure legend continues.) 
REM sleep in the first $3 \mathrm{~h}$ post-injection (Fig. 3E) was significantly reduced, suggesting the possibility that TMN ${ }^{\mathrm{HDC}}$ activation may limit transitions into REM sleep. In addition, administration of $\mathrm{CNO}$ significantly increased wakefulness in $\mathrm{HDC}^{\mathrm{hM} 3 \mathrm{Dq}}$ mice when exposed to the cage change challenge (Fig. 3G).

While activation of TMN ${ }^{\mathrm{HDC}}$ neurons was insufficient to appreciably alter arousal levels at baseline, it remains possible that $\mathrm{TMN}^{\mathrm{HDC}}$ neurons are necessary for maintaining normal sleepwake behavior. To further explore this possibility, we generated HDC-cre/ArchT-eGFP lox-STOP-lox mice (Daigle et al., 2018; henceforth $\mathrm{HDC}^{\text {ArchT-eGFP }}$ ) in which the orange light-activated inhibitory proton pump, ArchT (Han et al., 2011) is expressed in HDC neurons within the TMN (Fig. 4A,B). ArchT was expressed in $95.8 \pm 1.6 \%$ of $\mathrm{TMN}^{\mathrm{HDC}}$ neurons ( $n=2$ mice). To confirm that activation of the proton pump reliably inhibited HDC ${ }^{\text {ArchT-eGFP }}$ neurons, we performed electrophysiological recordings from fluorescently labeled HDC ${ }^{\text {ArchT-eGFP }}$ neurons in vitro (Fig. $4 C, D$ ). In brain slices, orange light exposure $(589 \mathrm{~nm})$ hyperpolarized HDC $^{\text {ArchT-eGFP }}$ neurons $(-5.53 \pm 0.31 \mathrm{mV} ; n=8$; paired $t$ test, control vs light on, $p<0.0001)$ and completely silenced all neurons tested ( $n=8$; paired $t$ test, control vs laser on, $p=0.0031$ ).

To determine the effect of inhibiting HDC neurons upon arousal, mice expressing ArchT in HDC neurons and littermate controls that did not express ArchT were equipped with headstages for recording EEG/EMG and bilateral optical fiber implants that were targeted over the ventral TMN (Fig. 4E). Sustained orange light pulses ( $589 \mathrm{~nm}, 15 \mathrm{~mW}, 5 \mathrm{~min}$ long) were delivered via the optical fibers to all mice following 2 min of active wake (Fig. $4 F$ ). We found that orange light inhibition of HDC ${ }^{\text {ArchT-eGFP }}$ neurons during waking did not decrease the latency to NREM sleep compared with orange light stimulation of the TMN in littermate controls (HDC ${ }^{\text {Arch-eGFP }}$ inhibition: $9.45 \pm$ 3.35 min; controls: $14.35 \pm 3.12 \min , n=6$ per group, $p=0.422$ independent sample $t$ test), and did not increase NREM sleep amount or delta power during the light pulse (Fig. 4G,H).

\section{Discussion \\ Principal findings}

An arousal-promoting role for the TMN histamine neurons has long been posited (Scammell et al., 2019), yet the precise mechanisms have remained unclear. A recent study has provided some insight into mechanism by showing that release of GABA from histaminergic neurons provides a tonic inhibition to the cortex and hence GABA release from histaminergic neurons may prevent hyperarousal resulting from unrestricted histamine activation of the cortex (Yu et al., 2015). To further explore this finding, we used genetic deletion approaches to chronically disrupt either GABA synthesis or transmission by $\mathrm{TMN}^{\mathrm{HDC}}$ neurons. Unexpectedly, we found that both manipulations were without effect on baseline arousal levels in the mouse. More surprisingly, we also found that very few $\mathrm{TMN}^{\mathrm{HDC}}$ neurons contain VGAT, leaving unresolved the mechanism(s) by which GABA may be released from TMN ${ }^{\mathrm{HDC}}$ neurons. We also show that chemogenetic

\section{$\leftarrow$}

(Figure legend continued.) Sidak post hoc test). $\boldsymbol{F}$, Total number of wake, NREM sleep, and REM sleep episodes following ZT3 saline (blue) or CNO (red) injection in HDC ${ }^{\text {M3Dq }}$ mice $(n=14$, mean + SEM, paired $t$ test). G, Average duration of wake, NREM sleep and REM sleep episodes following ZT3 saline (blue) or CNO (red) injection in HDC $C^{M 3 D q}$ mice $(n=14$, mean + SEM, paired $t$ test). $\boldsymbol{H}$, Hourly mean ( \pm SEM) amounts of wake, NREM sleep, and REM sleep in $H D C^{M 3}{ }^{3 D q}$ mice immediately following a clean cage change challenge after either a saline (blue) or CNO (red) injection at ZT6 ( $n=6$, two-way RM ANOVA followed by Sidak post hoc test, ${ }^{*} p<$ $0.05)$. activation of TMN ${ }^{\mathrm{HDC}}$ neurons does not increase wakefulness, except in the specific behavioral context of a cage change challenge, and that optogenetic inhibition of TMN ${ }^{\mathrm{HDC}}$ neurons does not promote or otherwise facilitate entry into NREM sleep.

\section{Technical limitations}

Although every effort was made to confirm the validity of our mouse lines, we do acknowledge an inherent limitation of our strategy, namely that Cre-recombinase is expressed at detectable levels in $\sim 75 \%$ of HDC neurons in our HDC-cre mouse line (Yanovsky et al., 2012). Although this is on a par with other available HDC-cre mouse lines (Zecharia et al., 2012; Fujita et al., 2017), it meant that we were unable to gain genetic access to the entire HDC population. We additionally observed slight ectopic recombination of cre-reporter genes in the dorsolateral geniculate and posterior nuclei of the thalamus, which has been reported previously and is consistent with other available HDC-cre mouse lines (Yanovsky et al., 2012; Zecharia et al., 2012). However, we do not believe expression of cre-recombinase in these neurons affected our results and conclusions for two main reasons: (1) These thalamic nuclei are not GABAergic and hence genetic deletion of GAD67 or VGAT in these neurons should have no effects, either behaviorally or molecularly. (2) With specific respect to our optogenetic inhibition experiments, our optical fibers were targeted specifically to the ventral TMN, which is anatomically distinct from the geniculate and posterior nuclei thalamic neurons expressing ArchT. It is also worth noting that the geniculate and posterior nuclei of the thalamus have no known role in arousal regulation (Fuller et al., 2011; Anaclet et al., 2015) and as such, modulating their activity would not be expected to have a major influence upon cortical arousal.

\section{The role of TMN ${ }^{\mathrm{HDC}}$ neurons in arousal regulation}

We believe that most of the experimental evidence in support of a wake-promoting role for the brain's histaminergic system is circumstantial at best (Scammell et al., 2019). For example, while histaminergic neurons are wake-active, they are not active before arousal (Takahashi et al., 2006), and hence unlikely to be truly involved in inducing arousal. In addition, while TMN ${ }^{\mathrm{HDC}}$ neurons are anatomically well positioned to exert a potent influence over the sleep-promoting network through their reciprocal connections with the sleep-promoting VLPO (Sherin et al., 1996, 1998; Chou et al., 2002; Zhang et al., 2015; Chung et al., 2017; Kroeger et al., 2018), a functional contribution of this pathway to arousal control remains unconfirmed. Ablation of TMN ${ }^{\mathrm{HDC}}$ neurons (Denoyer et al., 1991; Gerashchenko et al., 2004; BlancoCenturion et al., 2007) also has strikingly little effect upon sleep and arousal. Similarly, studies using HDC knock-out mice or the HDC- $\Delta \gamma_{2}$ mouse (the latter of which bears a gain of function mutation that renders HDC neurons more excitable due to selective $\mathrm{GABA}_{\mathrm{A}}$ receptor deletion in HDC neurons), have also revealed little quantitative or qualitative alterations in baseline sleep-wake (Parmentier et al., 2002; Anaclet et al., 2009; Zecharia et al., 2012). However, HDC-containing neurons may be necessary for maintaining a higher level of vigilance in response to a behavioral challenge such as a novel environment (cage change), because HDC knock-out mice fall asleep more quickly whereas HDC- $\Delta \gamma_{2}$ mice maintain arousal for considerably longer following exposure to the novel environment (Parmentier et al., 2002; Zecharia et al., 2012). Our findings of an absence of effect of acute activation or inhibition of TMN ${ }^{\mathrm{HDC}}$ neurons on sleep-wake quantities, but enhancement of arousal following a cage change challenge, is remarkably consistent with findings from the studies 
A

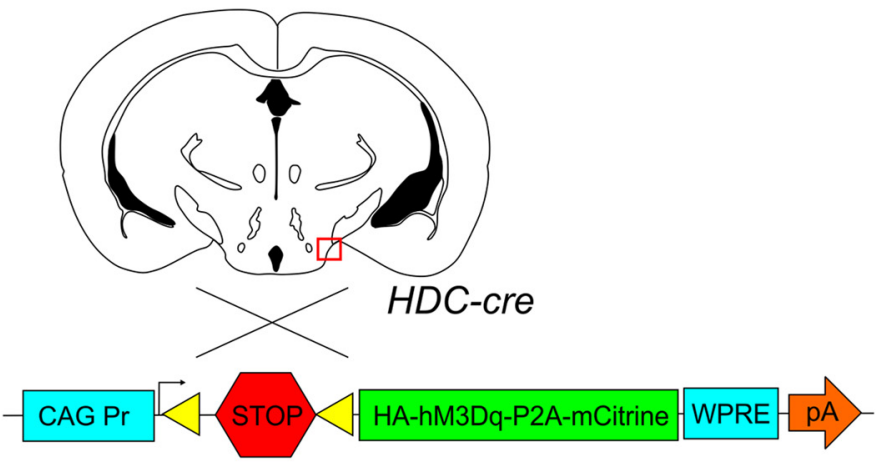

B
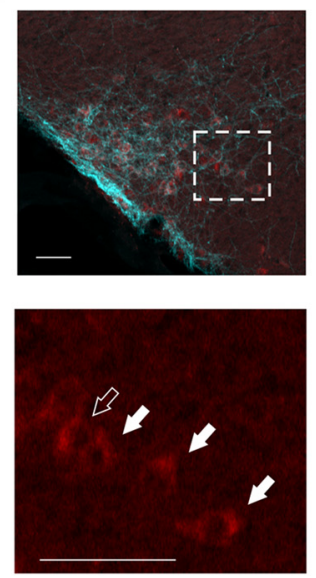

HDC
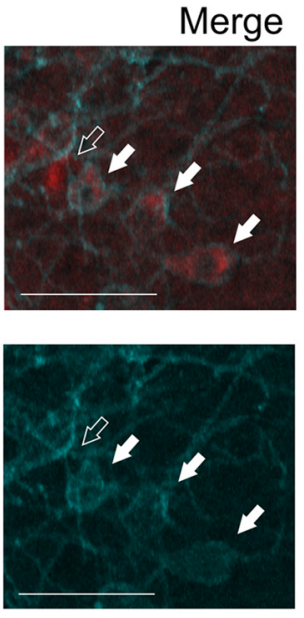

HA-tag

\section{C}
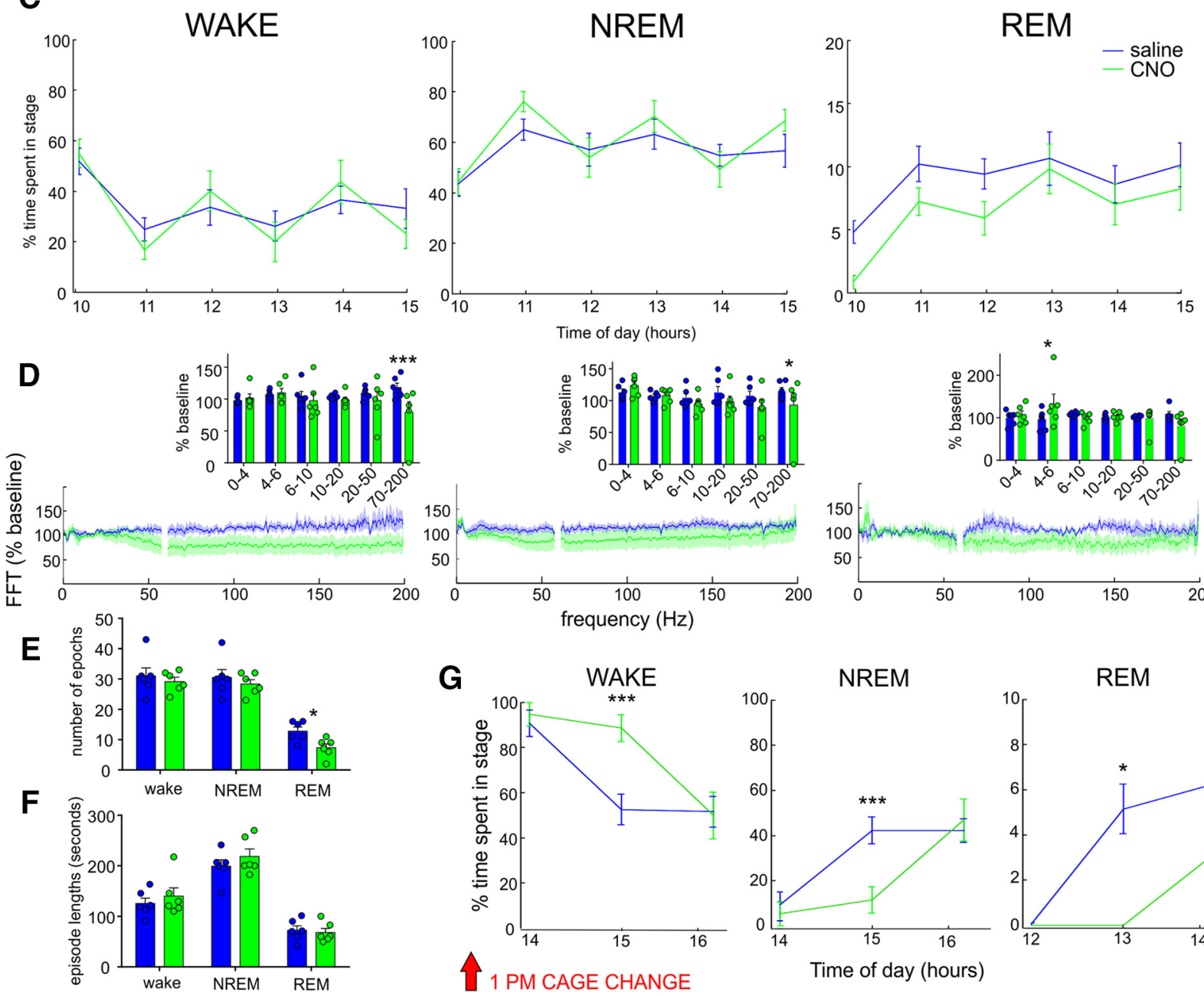

\section{G}

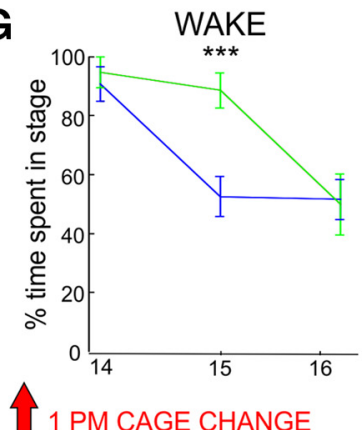

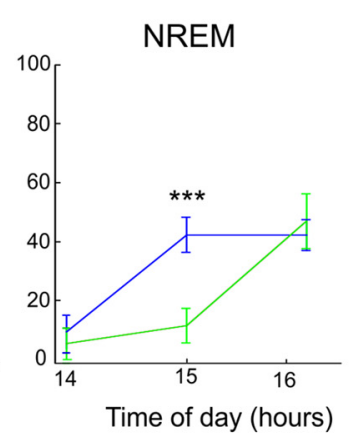

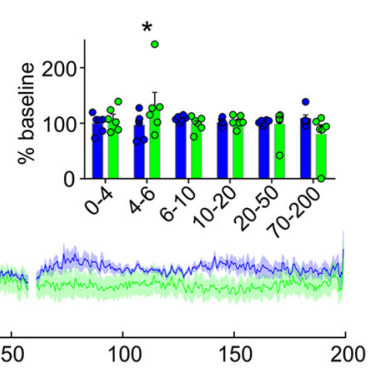

Figure 3. Chemogenetic activation of TMN ${ }^{H D C}$ neurons in the $H D C^{h M 3 D q}$ reporter mouse does not enhance arousal under baseline conditions but increases wakefulness following a clean cage change challenge. $A$, Schematic of the genetic cross used to generate $H D C C^{h} 3 D q$ mice. $B$, Top left, Photomicrograph illustrating colabeling (white) of HDC IR (red) and HA-tag expression (cyan), in the ventral TMN. The white boxed area is shown at higher magnification (top right) and in split color channels (bottom). White filled arrows label neurons coexpressing HA-hM3Dq-mCitrine and HDC. Open arrows indicate neurons expressing HDC only. Scale bar, $50 \mu \mathrm{m}$. C, Hourly mean ( \pm SEM) amounts of wake, NREM sleep, and REM sleep in HDC ${ }^{\mathrm{hM} 3 D q}$ mice following ZT3 saline (blue) and CNO (green) injection ( $n=6$ ). D, FFT of EEG spectrogram during wake, NREM sleep and REM sleep following ZT3 saline (blue) or CNO (green) injection in HDC ${ }^{\mathrm{hM} 3 \mathrm{D} q}$ mice. Insets: Mean spectral power ( $n=$ 6, two-way RM ANOVA followed by Sidak post hoc test, ${ }^{*} p<0.05,{ }^{* * *} p<0.001$ ). $\boldsymbol{E}$, Total number of wake, NREM sleep and REM sleep episodes following ZT3 saline (blue) or CN0 (green) injection in $H D C^{h M 3 D q}$ mice $\left(n=6\right.$, mean + SEM, paired $t$ test, ${ }^{*} p<0.05$ ). $F$, Average duration of wake, NREM sleep and REM sleep episodes following ZT3 saline (blue) or CNO (green) injection in HDC ${ }^{h M 3 D q}$ mice ( $n=6$, mean + SEM, paired $t$ test). $\mathbf{G}$, Hourly mean ( \pm SEM) amounts of wake, NREM sleep and REM sleep in $H D C^{h M 3 D q}$ mice immediately following a clean cage change challenge after either a saline (blue) or CNO (green) injection at ZT6 ( $n=6$, two-way RM ANOVA followed by Sidak post hoc test, $\left.{ }^{*} p<0.05,{ }^{* * *} p<0.001\right)$. 

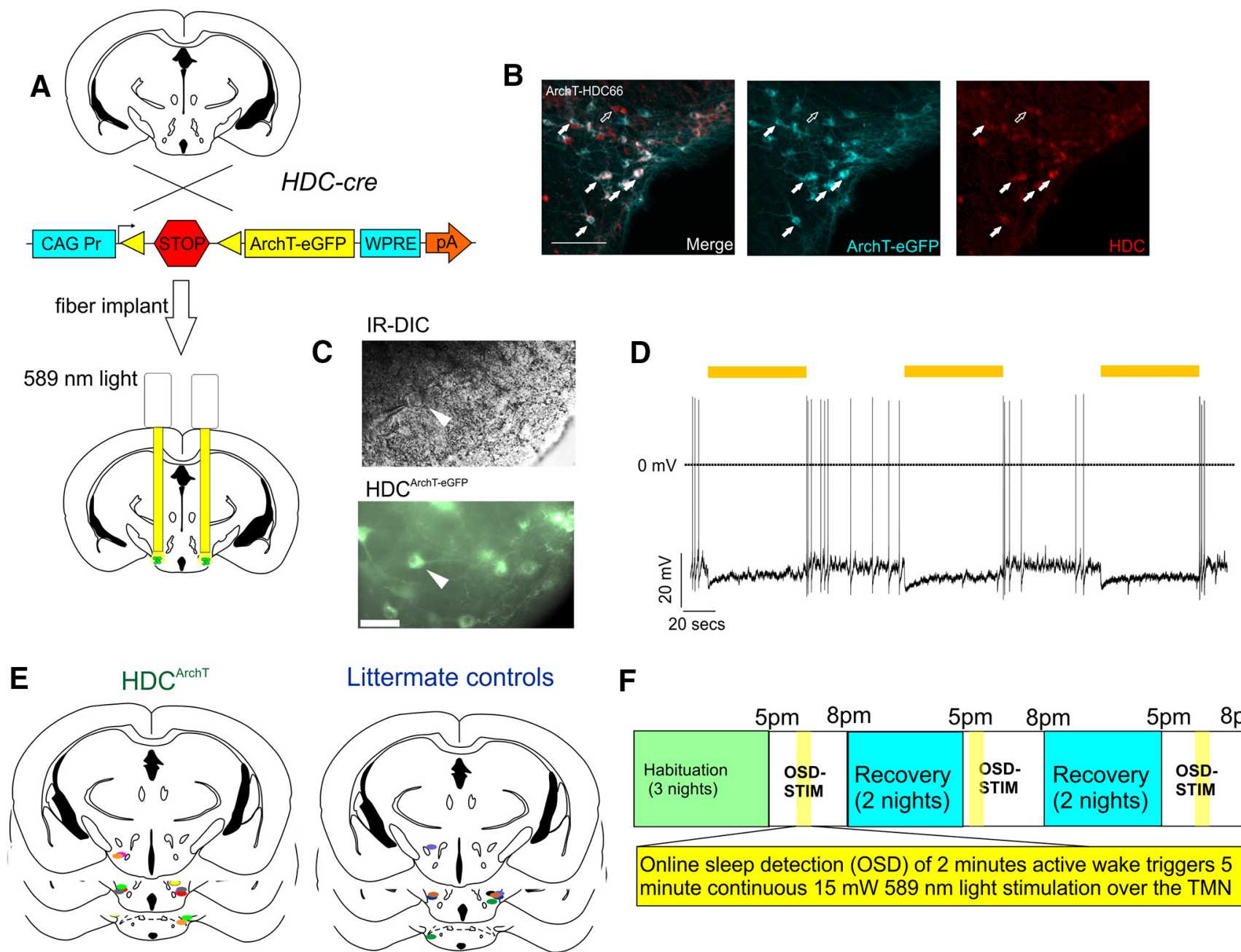

Littermate controls

$\mathbf{F}$

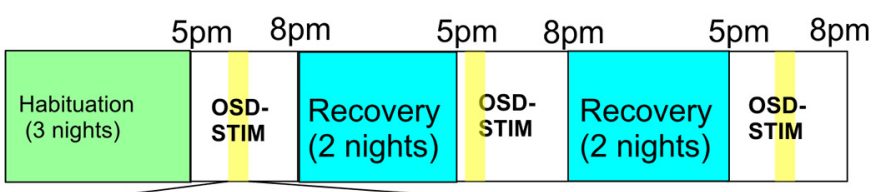

Online sleep detection (OSD) of 2 minutes active wake triggers 5 minute continuous $15 \mathrm{~mW} 589 \mathrm{~nm}$ light stimulation over the TMN
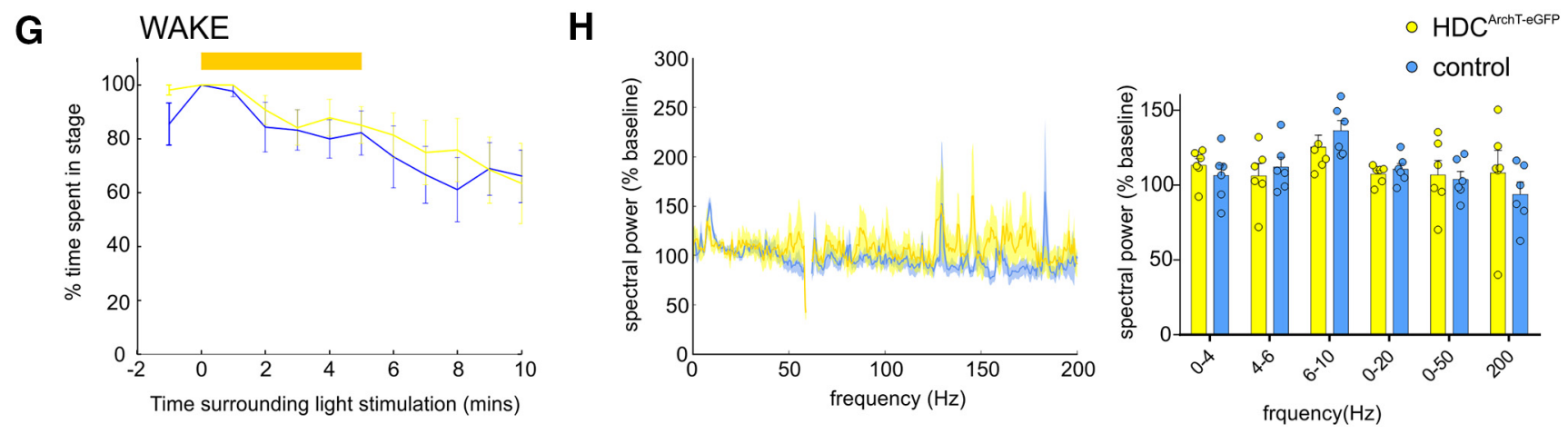

Figure 4. Optogenetic inhibition of TMN ${ }^{H D C}$ neurons does not promote sleep. A, Top, Schematic of the genetic cross used to generate HDC ${ }^{\text {ArchT-eGFP }}$ mice. Bottom, Schematic of optogenetic bilateral fiber targeting to ventral TMN ${ }^{H D C}$ neurons. $\boldsymbol{B}$, Photomicrograph illustrating coexpression (white, left) of ArchT-eGFP (cyan, middle), and HDC IR (red, right), in the ventral TMN. White filled arrows indicate colabeled neurons; the white open arrow indicates a neuron expressing HDC only. Scale bar, $100 \mu \mathrm{m}$. C, Top, IR-DIC image of a recorded HDC ArchT-eGFP neuron. Bottom, Native

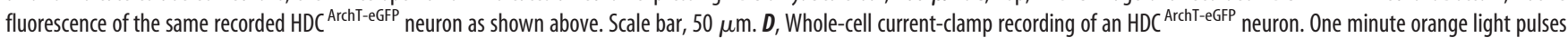
(yellow bars above the recording) inhibited action potential firing and hyperpolarized HDC ArchT-eGFP neurons. $\boldsymbol{E}$, Optical fiber placements in HDC ArchT-eGFP mice and littermate controls. $\boldsymbol{F}$, Experimental schema. G, Minute-by-minute wake (mean \pm SEM) in HDC ArchT-eGFP mice (yellow) and littermate controls (blue) for 2 min preceding optogenetic inhibition, throughout the duration of the inhibition and 5 min after cessation of the inhibitory light pulse ( $n=6$ per group, two-way ANOVA with Sidak post hoc test). The orange bar indicates the inhibitory light pulse. $\boldsymbol{H}$, Left, FFT of EEG spectrogram during wake during the optogenetic light pulse in HDC ${ }^{\text {Archt-eGFP }}$ mice (yellow) and littermate controls (blue). Power is expressed as percentage of the baseline power. Right, Mean ( + SEM) power in spectral frequency bands ( $n=6$ per group, two-way ANOVA, followed by Sidak post hoc test).

using the HDC knock-out and HDC- $\Delta \gamma_{2}$ mouse lines. Our data are also consistent with a prior study that found increased motor activity in an open-field assay, essentially a novel environment, following chemogenetic activation of TMN ${ }^{\mathrm{HDC}}$ neurons (Yu et al., 2015).
It was recently reported that acute optogenetic inhibition of $\mathrm{TMN}^{\mathrm{HDC}}$ neurons promotes NREM sleep (Fujita et al., 2017). We found that activation of ArchT robustly inhibited TMN ${ }^{\text {HDC }}$ neurons in our ex vivo slices, but we did not observe increased NREM sleep following optogenetic inhibition of TMN ${ }^{\mathrm{HDC}}$ neu- 
rons. Although this finding was surprising given the previous report, we note several important methodological differences between our study and that by Fujita et al. (2017). These differences include, but are not limited to, the use of different mouse lines, Arch variants and receptor expression strategies (viral vector transduction compared with cre-conditional expression of ArchT in the mouse line), one or more of which could have contributed to the discrepant findings.

Another important difference in findings between our work and a previous report was the extent of coexpression of VGAT in HDC neurons. We found that few TMN ${ }^{\mathrm{HDC}}$ neurons contain VGAT, whereas previous work emphasized the importance of VGAT-dependent GABA release from histamine neurons in preventing hyperarousal (Yu et al., 2015). Given the high percentage of TMN ${ }^{\mathrm{HDC}}$ neurons that contain GAD67 (and therefore, presumably GABA), we ask, might an alternative GABA release mechanism exist in TMN ${ }^{\mathrm{HDC}}$ neurons? This is not without precedent since dopaminergic neurons of the midbrain package GABA into vesicles for release using the vesicular monoamine transporter (Tritsch et al., 2012) and it is possible that a similar mechanism exists for GABA release from histamine neurons. To this end, histaminergic neurons express the vesicular monoamine transporter-2 (vMAT2; Merickel and Edwards, 1995; De Luca et al., 2016), although vMAT2 in TMN neurons colocalizes with histamine, not GABA, so it is an unlikely vesicular transporter for GABA (Kukko-Lukjanov and Panula, 2003).

\section{Conclusion}

Our findings demonstrate that TMN ${ }^{\mathrm{HDC}}$ neurons play little role in maintaining baseline behavioral and EEG arousal, but they do promote arousal during exposure to a novel environment, as previously suggested by others (Parmentier et al., 2002; Zecharia et al., 2012). We would thus argue that our findings are generally congruent with much of the extant literature regarding the role of histamine in arousal control; that is, TMN ${ }^{\text {HDC }}$ neurons are not essential to, or otherwise necessary for, normal levels of arousal. The surprising finding that very few $\mathrm{TMN}^{\mathrm{HDC}}$ neurons contain VGAT does not necessarily negate the possibility that GABA may be released from histaminergic neurons to constrain arousal, as previously proposed, although it does invite the question of how targeted knockdown of VGAT in TMN ${ }^{\mathrm{HDC}}$ neurons produced the potent arousal effects that were previously reported. Future experiments using transcriptomics on TMN ${ }^{\mathrm{HDC}}$ neurons should help uncover subcellular factors that may enable TMN ${ }^{\mathrm{HDC}}$ neurons to release GABA.

In summary, our findings, together with the majority of studies investigating the role of histamine in the arousal system, support the concept that TMN histamine is required for vigilance maintenance under certain environmental and/or behavioral contexts but is neither necessary nor sufficient to promote EEG or behavioral wake at baseline.

\section{References}

Airaksinen MS, Alanen S, Szabat E, Visser TJ, Panula P (1992) Multiple neurotransmitters in the tuberomammillary nucleus: comparison of rat, mouse, and guinea pig. J Comp Neurol 323:103-116.

Amaral DG, Price JL (1983) An air pressure system for the injection of tracer substances into the brain. J Neurosci Methods 9:35-43.

Anaclet C, Parmentier R, Ouk K, Guidon G, Buda C, Sastre, J-P, Akaoka H, Sergeeva OA, Yanagisawa M, Ohtsu H, Franco P, Haas HL, Lin JS (2009) Orexin/hypocretin and histamine: distinct roles in the control of wakefulness demonstrated using knock-out mouse models. J Neurosci 29: 14423-14438.

Anaclet C, Pedersen NP, Ferrari LL, Venner A, Bass CE, Arrigoni E, Fuller PM
(2015) Basal forebrain control of wakefulness and cortical rhythms. Nat Commun 6:8744.

Armbruster BN, Li X, Pausch MH, Herlitze S, Roth BL (2007) Evolving the lock to fit the key to create a family of $\mathrm{G}$ protein-coupled receptors potently activated by an inert ligand. Proc Natl Acad Sci U S A 104:5163-5168.

Blanco-Centurion C, Gerashchenko D, Shiromani PJ (2007) Effects of saporin-induced lesions of three arousal populations on daily levels of sleep and wake. J Neurosci 27:14041-14048.

Burgess CR, Oishi Y, Mochizuki T, Peever JH, Scammell TE (2013) Amygdala lesions reduce cataplexy in orexin knock-out mice. J Neurosci 33:9734-9742.

Chou TC, Bjorkum AA, Gaus SE, Lu J, Scammell TE, Saper CB (2002) Afferents to the ventrolateral preoptic nucleus. J Neurosci 22:977-990.

Chung S, Weber F, Zhong P, Tan CL, Nguyen TN, Beier KT, Hörmann N, Chang, WC, Zhang Z, Do JP, Yao S, Krashes MJ, Tasic B, Cetin A, Zeng H, Knight ZA, Luo L, Dan Y (2017) Identification of preoptic sleep neurons using retrograde labelling and gene profiling. Nature 545:477-481.

Daigle TL, Madisen L, Hage TA, Valley MT, Knoblich U, Larsen RS, Takeno MM, Huang L, Gu H, Larsen R, Mills M, Bosma-Moody A, Siverts LA, Walker M, Graybuck LT, Yao Z, Fong O, Nguyen TN, Garren E, Lenz GH, et al. (2018) A suite of transgenic driver and reporter mouse lines with enhanced brain-cell-type targeting and functionality. Cell 174:465-480.e422.

Dauvilliers Y, Bassetti C, Lammers GJ, Arnulf I, Mayer G, Rodenbeck A, Lehert P, Ding, CL, Lecomte, JM, Schwartz, JC (2013) Pitolisant versus placebo or modafinil in patients with narcolepsy: a double-blind, randomised trial. Lancet Neurol 12:1068-1075.

De Luca R, Suvorava T, Yang D, Baumgärtel W, Kojda G, Haas HL, Sergeeva OA (2016) Identification of histaminergic neurons through histamine 3 receptor-mediated autoinhibition. Neuropharmacology 106:102-115.

Denoyer M, Sallanon M, Buda C, Kitahama K, Jouvet M (1991) Neurotoxic lesion of the mesencephalic reticular formation and/or the posterior hypothalamus does not alter waking in the cat. Brain Res 539:287-303.

Fujita A, Bonnavion P, Wilson MH, Mickelsen LE, Bloit J, de Lecea L, Jackson AC (2017) Hypothalamic tuberomammillary nucleus neurons: electrophysiological diversity and essential role in arousal stability. J Neurosci 37:9574-9592.

Fuller PM, Sherman D, Pedersen NP, Saper CB, Lu J (2011) Reassessment of the structural basis of the ascending arousal system. J Comp Neurol 519: 933-956.

Geerling JC, Yokota S, Rukhadze I, Roe D, Chamberlin NL (2017) Köllikerfuse GABAergic and glutamatergic neurons project to distinct targets. J Comp Neurol 525:1844-1860.

Gerashchenko D, Chou TC, Blanco-Centurion CA, Saper CB, Shiromani PJ (2004) Effects of lesions of the histaminergic tuberomammillary nucleus on spontaneous sleep in rats. Sleep 27:1275-1281.

Han X, Chow BY, Zhou H, Klapoetke N, Chuong A, Rajimehr R, Yang A, Baratta MV, Winkle J, Desimone R, Boyden E (2011) A high-light sensitivity optical neural silencer: development and application to optogenetic control of non-human primate cortex. Front Syst Neurosci 5:18.

Kroeger D, Absi G, Gagliardi C, Bandaru SS, Madara JC, Ferrari LL, Arrigoni E, Münzberg H, Scammell TE, Saper CB, Vetrivelan R (2018) Galanin neurons in the ventrolateral preoptic area promote sleep and heat loss in mice. Nat Commun 9:4129.

Krystal AD, Richelson E, Roth T (2013) Review of the histamine system and the clinical effects of $\mathrm{H} 1$ antagonists: basis for a new model for understanding the effects of insomnia medications. Sleep Med Rev 17:263-272.

Kukko-Lukjanov TK, Panula P (2003) Subcellular distribution of histamine, GABA and galanin in tuberomamillary neurons in vitro. J Chem Neuroanat 25:279-292.

Lin JS, Dauvilliers Y, Arnulf I, Bastuji H, Anaclet C, Parmentier R, Kocher L, Yanagisawa M, Lehert P, Ligneau X, Perrin D, Robert P, Roux M, Lecomte JM, Schwartz JC (2008) An inverse agonist of the histamine H3 receptor improves wakefulness in narcolepsy: studies in orexin ${ }^{-1-}$ mice and patients. Neurobiol Dis 30:74-83.

Merickel A, Edwards RH (1995) Transport of histamine by vesicular monoamine transporter-2. Neuropharmacology 34:1543-1547.

Mochizuki T, Yamatodani A, Okakura K, Takemura M, Inagaki N, Wada H (1991) In vivo release of neuronal histamine in the hypothalamus of rats measured by microdialysis. Naunyn Schmiedebergs Arch Pharmacol 343: 190-195.

Obata K, Hirono M, Kume N, Kawaguchi Y, Itohara S, Yanagawa Y (2008) 
GABA and synaptic inhibition of mouse cerebellum lacking glutamate decarboxylase 67. Biochem Biophys Res Commun 370:429-433.

Parmentier R, Ohtsu H, Djebbara-Hannas Z, Valatx JL, Watanabe T, Lin JS (2002) Anatomical, physiological, and pharmacological characteristics of histidine decarboxylase knock-out mice: evidence for the role of brain histamine in behavioral and sleep-wake control. J Neurosci 22:7695-7711.

Paxinos GT, Franklin K (2001) The mouse brain in stereotaxic coordinates, Ed 2. San Diego: Academic.

Scammell TE, Jackson AC, Franks NP, Wisden W, Dauvilliers Y (2019) Histamine: neural circuits and new medications. Sleep 42:zsy183.

Senba E, Daddona PE, Watanabe T, Wu JY, Nagy JI (1985) Coexistence of adenosine deaminase, histidine decarboxylase, and glutamate decarboxylase in hypothalamic neurons of the rat. J Neurosci 5:3393-3402.

Sherin JE, Shiromani PJ, McCarley RW, Saper CB (1996) Activation of ventrolateral preoptic neurons during sleep. Science 271:216-219.

Sherin JE, Elmquist JK, Torrealba F, Saper CB (1998) Innervation of histaminergic tuberomammillary neurons by GABAergic and galaninergic neurons in the ventrolateral preoptic nucleus of the rat. J Neurosci 18:4705-4721.

Szakacs Z, Dauvilliers Y, Mikhaylov V, Poverennova I, Krylov S, Jankovic S, Sonka K, Lehert P, Lecomte I, Lecomte JM, Schwartz JC, Schwartz JC (2017) Safety and efficacy of pitolisant on cataplexy in patients with narcolepsy: a randomised, double-blind, placebo-controlled trial. Lancet Neurol 16:200-207.

Takahashi K, Lin JS, Sakai K (2006) Neuronal activity of histaminergic tuberomammillary neurons during wake-sleep states in the mouse. J Neurosci 26:10292-10298.

Takeda N, Inagaki S, Shiosaka S, Taguchi Y, Oertel WH, Tohyama M, Watanabe T, Wada H (1984) Immunohistochemical evidence for the coexistence of histidine decarboxylase-like and glutamate decarboxylaselike immunoreactivities in nerve cells of the magnocellular nucleus of the posterior hypothalamus of rats. Proc Natl Acad Sci U S A 81:7647-7650.

Tong Q, Ye CP, Jones JE, Elmquist JK, Lowell BB (2008) Synaptic release of
GABA by AgRP neurons is required for normal regulation of energy balance. Nat Neurosci 11:998-1000.

Tritsch NX, Ding JB, Sabatini BL (2012) Dopaminergic neurons inhibit striatal output through non-canonical release of GABA. Nature 490:262-266.

Venner A, Anaclet C, Broadhurst RY, Saper CB, Fuller PM (2016) A novel population of wake-promoting GABAergic neurons in the ventral lateral hypothalamus. Curr Biol 26:2137-2143.

Walker AK, Park WM, Chuang JC, Perello M, Sakata I, Osborne-Lawrence S, Zigman JM (2013) Characterization of gastric and neuronal histaminergic populations using a transgenic mouse model. PLoS One 3:e60276.

Williams RH, Chee MJ, Kroeger D, Ferrari LL, Maratos-Flier E, Scammell TE, Arrigoni E (2014) Optogenetic-mediated release of histamine reveals distal and autoregulatory mechanisms for controlling arousal. J Neurosci 34:6023-6029.

Yanovsky Y, Zigman JM, Kernder A, Bein A, Sakata I, Osborne-Lawrence S, Haas HL, Sergeeva OA (2012) Proton- and ammonium-sensing by histaminergic neurons controlling wakefulness. Front Syst Neurosci 6:23.

Yu X, Ye Z, Houston CM, Zecharia AY, Ma Y, Zhang Z, Uygun DS, Parker S, Vyssotski AL, Yustos R, Franks NP, Brickley SG, Wisden W (2015) Wakefulness is governed by GABA and histamine cotransmission. Neuron 87:164-178.

Zecharia AY, Yu X, Götz T, Ye Z, Carr DR, Wulff P, Bettler B, Vyssotski AL, Brickley SG, Franks NP, Wisden W (2012) GABAergic inhibition of histaminergic neurons regulates active waking but not the sleepwake switch or propofol-induced loss of consciousness. J Neurosci 32:13062-13075.

Zhang Z, Ferretti V, Güntan İ, Moro A, Steinberg EA, Ye Z, Zecharia AY, Yu X, Vyssotski AL, Brickley SG, Yustos R, Pillidge ZE, Harding EC, Wisden W, Franks NP (2015) Neuronal ensembles sufficient for recovery sleep and the sedative actions of $\alpha 2$ adrenergic agonists. Nat Neurosci 18:553-561.

Zhu H, Aryal DK, Olsen RH, Urban DJ, Swearingen A, Forbes S, Roth BL, Hochgeschwender U (2016) Cre-dependent DREADD (designer receptors exclusively activated by designer drugs) mice. Genesis 54:439-446. 